\title{
ANALISIS ZONA SELAMAT SEKOLAH (ZoSS) DI KECAMATAN DENPASAR SELATAN (STUDI KASUS: SDN 5 PEDUNGAN DAN SEKOLAH HARAPAN)
}

\author{
I Made Kariyana1), I Komang Alit Astrawan Putra'), dan I Nyoman Arta Wijaya1) \\ 1) Jurusan Teknik Sipil, Universitas Ngurah Rai, Denpasar, Bali \\ madekariyana@gmail.com
}

\begin{abstract}
SDN 5 Pedungan and Harapan School are schools in South Denpasar District which already have School Safety Zone (SSZ) facilities. The two schools are traversed by a fairly high traffic volume due to the large number of trip generation centers located along the road such as traders, education, and industry. This study aims to analyze the level of effectiveness of SSZ in both schools through which the traffic volume is quite high compared to other schools. The field survey was carried out by recording the vehicle travel time when crossing ZoSS at a distance of $100 \mathrm{~m}$. The effectiveness level of SSZ was analyzed using Regulation of the Director General of Land Transportation in 2006, 2014, and 2018. The results of the analysis showed that the application of SSZ in South Denpasar District was not effective, the average percentage of vehicles compliant when crossing SSZ for SDN 5 Pedungan was 42.67\%, which means that SSZ is quite effective and Hope School is $32.34 \%$ which means SSZ is less effective.
\end{abstract}

Keywords: effectiveness, traffic, SSZ

\begin{abstract}
ABSTRAK
SDN 5 Pedungan dan Sekolah Harapan merupakan sekolah di Kecamatan Denpasar Selatan yang sudah memiliki fasilitas Zona Selamat Sekolah (ZoSS). Kedua sekolah tersebut dilalui volume lalu lintas yang cukup tinggi karena banyaknya pusat bangkitan pergerakan yang berlokasi disepanjang jalan seperti pedagang, pendidikan dan industri. Penelitian ini bertujuan untuk menganalisis tingkat efektivitas ZoSS di kedua sekolah tersebut yang dilalui volume lalu lintas cukup tinggi dibandingkan dengan sekolah lainya. Survey lapangan dilakukan dengan mencatat waktu tempuh kendaraan saat melintasi ZoSS pada jarak $100 \mathrm{~m}$. Tingkat efektivitas ZoSS dianalisa dengan menggunakan Peraturan Direktur Jendral Perhubungan Darat tahun 2006, 2014, dan 2018. Hasil analisis menunjukan bawha penerapan ZoSS di Kecamatan Denpasar Selatan tidak efektif, ratarata prosentase kendaraan patuh saat melintasi ZoSS untuk SDN 5 Pedungan adalah 42.67\% yang artinya ZoSS cukup efektif dan Sekolah Harapan adalah $32.34 \%$ yang artinya ZoSS kurang efektif.
\end{abstract}

Kata kunci: efektifitas, lalu lintas, ZoSS 


\section{PENDAHULUAN}

Pertumbuhan pembangunan saat ini berjalan sangat pesat, hal ini terwujud dari pemukiman penduduk yang semakin bertambah banyak khususnya di Kota Denpasar yang memiliki luas wilayah 124 $\mathrm{km}^{2}$ dengan jumlah penduduk 930600 jiwa (BPS, 2018). Hal tersebut berpengaruh terhadap meningkatnya arus pergerakan manusia dan barang yang mempunyai dampak negatif yaitu meningkatnya tingkat kecelakaan lalu lintas. Pembangunan dibidang angkutan jalan saat ini mengutamakan keselamatan dan penertiban lalu lintas, dengan harapan menurunkan angka kecelakaan lalu lintas, baik yang dipengaruhi oleh faktor teknis (sarana dan prasarana) maupun oleh pengguna jalan (pengemudi dan pejalan kaki). Salah satu upaya pemerintah kota Denpasar untuk menjaga keselamatan anak sekolah adalah dengan menyediakan fasilitas Zona Selamat Sekolah (ZoSS) yang di posisikan sebelum tempat penyebrangan untuk memberikan peringatan kepada pengendara kendaraan bermotor untuk menurunkan kecepatan.

Zona Selamat Sekolah (ZoSS) adalah pengendalian kegiatan lalu lintas melalui pengaturan kecepatan dengan penempatan marka dan rambu pada ruas jalan dilingkungan sekolah yang bertujuan untuk mencegah terjadinya kecelakaan sebagai upaya menjamin keselamatan anak disekolah. Zona Selamat Sekolah (ZoSS) didesain agar kendaraan yang melewati daerah ZoSS berada dalam kecepatan rendah (maksimal $30 \mathrm{~km} / \mathrm{jam}$ ), sehingga memberikan waktu reaksi antisipasi gerakan anak sekolah yang umumnya bersifat spontan dan tidak terduga. (Anonim, 2018).

Beberapa sekolah di Kecamatan Denpasar Selatan sudah dilengkapi Zona Selamat Sekolah (ZoSS) antara lain SDN 5 Pedungan dan Sekolah Harapan. Dimana dari 2 sekolah tersebut dilalui volume lalu lintas tinggi, karena banyak pusat bangkitan pergerakan berlokasi disepanjang jalan, seperti perdagangan, pendidikan dan industri. Hal ini sering sekali menyebabkan kemacetan dikawasan ZoSS, keadaan seperti ini sangat membahayakan pejalan kaki khusunya anak-anak yang pergi kesekolah dan pulang sekolah, karena mereka merupakan pengguna jalan yang kurang hati-hati.

Berdasarkan hasil penelitian sebelumnya yang dilakukan oleh Ferryanto (2013) di ZoSS Jalan Surapati Denpasar bahwa $91.47 \%$ pengemudi kendaraan bermotor melanggar batas kecepatan maksimum yang telah ditetapkan pada kawasan ZoSS. Ini disebabkan oleh 
rambu-rambu yang tidak lengkap, kerusakan pada rambu-rambu dan marka yang sudah memudar. Sehingga pengendara tidak sadar telah memasuki kawasan ZoSS. Nurhakim, Sriastuti, \& Ardantha (2018) juga telah menganalisis efektifitas ZoSS dan kinerja ruas jalan di SDN 4 Dalung, dimana hasil studi menunjukkan tingkat perilaku penyeberang adalah $60.01 \%$ artinya ZoSS efektif. Tingkat perilaku pengantar adalah $67.65 \%$ artinya ZoSS efektif. Prosentase kendaraan yang mengikuti peraturan ZoSS adalah $32.58 \%$ artinya ZoSS kurang efektif. Kinerja ruas jalan pada segmen ZoSS memiliki derajat kejenuhan sebesar 0.09 tingkat pelayanan $\mathrm{A}$.

Oleh karena itu, perlu dilakukan penelitian lebih lanjut dikawasan ZoSS lainya. Penelitian ini bertujuan untuk menganalisis tingkat efektivitas ZoSS di Kecamatan Denpasar Selatan.

\section{KAJIAN PUSTAKA}

\subsection{ZoSS}

ZoSS adalah bagian dari kegiatan manajemen dan rekayasa lalu lintas berupa kegiatan pemberian prioritas keselamatan dan kenyamanan pejalan kaki pada kawasan sekolah (Anonim, 2018). ZoSS adalah lokasi diruas jalan tertentu yang merupakan zona kecepatan berbasis waktu untuk mengatur kecepatan kendaraan dilingkungan sekolah (Anonim, 2006).

Pada dasarnya semua sekolah berhak untuk menerapkan program ZoSS ini, namun dalam pelaksananya perlu ditentukan prioritas sekolah yang harus didahulukan antara lain:

1. Situasi sekolah dengan lalu lintas disekitarnya yang membahayakan anak murid, seperti kecepatan kendaraan yang melintas tinggi dan volume lalu lintas tinggi.

2. Situasi sekolah dengan kemacetan lalu lintas yang menyulitkan untuk berjalan kaki, bersepeda dan menjangkau angkutan umum.

3. Sekolah yang sangat antusias dan didukung pihak swasta, masyarakat, dan pemerintah untuk menjalankan program ZoSS.

Waktu operasi ZoSS direkomendasikan 2 (dua) jam dipagi hari dan 2 (dua) jam disiang hari, yaitu antara pagi pukul 06.30-08.30 dan antara siang pukul 12.00-14.00 dilaksanakan pada hari sekolah dan waktu operasi ZoSS tidak dilaksanakan pada hari libur. Waktu operasi ZoSS ini dapat disesuaikan dengan kebutuhan. Perpanjangan waktu operasi 
ZoSS dimungkinkan apabila selama waktu operasi ZoSS terdapat jumlah murid yang signifikan yang menyebabkan secara teratur sepanjang hari. Waktu operasi ZoSS dinyatakan dengan papan tambahan pada rambu-rambu lalu lintas (Anonim, 2006).

\subsection{Efektivitas}

Efektivitas ZoSS adalah zona yang bertujuan untuk mencegah terjadinya kecelakaan guna menjamin keselamatan anak disekolah (Anonim, 2014). Dengan menggunakan data survey kecepatan kendaraan, suatu kendaraan dianggap mematuhi peraturan jika kecepatan yang digunakan saat melintasi ZoSS $\leq 30$ $\mathrm{km} / \mathrm{jam}$. Persamaan yang digunakan adalah sebagai berikut:

$$
\frac{\sum p}{n} \times 100 \%
$$

dimana:

$\mathrm{p}:$ jumlah kendaraan patuh

$\mathrm{n}$ : jumlah sampel

\section{Tabel 1. Hubungan Tingkat Kepatuhan Terhadap Tingkat Efektivitas ZoSS}

\begin{tabular}{cc}
\hline $\begin{array}{c}\text { Tingkat } \\
\text { Kepatuhan }\end{array}$ & Tingkat Efektivitas \\
\hline $80 \%-100 \%$ & Sangat Efektif \\
$60 \%-79.99 \%$ & Efektif \\
$40 \%-59.99 \%$ & Cukup Efektif \\
$20 \%-39.99 \%$ & Kurang Efektif \\
$0 \%-19.99 \%$ & Tidak Efektif \\
\hline
\end{tabular}

Sumber: Sugiono, 2012

\subsection{Kecepatan Tempuh}

Manual Kapasitas Jalan Indonesia (MKJI) tahun 1997 menggunakan kecepatan tempuh sebagai ukuran utama kinerja segmen jalan, karena mudah dimengerti dan diukur, dan merupakan masukan yang penting untuk biaya pemakai jalan dalam analisis ekonomi. Kecepatan tempuh didefinisikan segmen jalan, untuk pengukuran kecepatan tempuh tersebut dapat digunakan rumus yaitu (Anonim, 1997):

$$
\begin{aligned}
& \mathrm{V}=\frac{d}{t} \\
& \text { dimana: } \\
& \mathrm{V}=\text { kecepatan rata-rata tempuh } \\
& \text { kendaraan }(\mathrm{km} / \mathrm{jam}) \\
& \mathrm{d}=\text { panjang segmen jalan yang } \\
& \text { diamati. } \\
& \mathrm{t} \text { = waktu rata-rata yang digunakan }
\end{aligned}
$$

\section{METODE PENELITIAN}

\subsection{Survey Pendahulan}

Survey pendahuluan dilakukan untuk mendapatkan data-data awal pada kondisi existing, Survey pendahuluan dilaksanakan pada 28 November 2019, dari survey ini didapat beberapa hal, seperti: lokasi keberadaan ZoSS di daerah survey, rambu- 
rambu yang berlaku dan data existing lainnya. Survey pendahuluan ini akan dijadikan sebagai tolak ukur dalam penentuan lokasi survey di kawasan tersebut.

\subsection{Lokasi Survey}

Kota Denpasar memiliki empat Kecamatan antara lain Kecamatan Denpasar Utara, Kecamatan Denpasar Barat, Kecamatan Denpasar Timur dan Kecamatan Denpasar Selatan. Penelitian ini dilakukan di Kecamatan Denpasar Selatan dengan memilih sekolah yang sudah ada fasilitas ZoSS yaitu SDN 5 Pedungan dan Sekolah Harapan yang dilalui volume lalu cukup tinggi dibandingkan dengan sekolah lainya, karena banyak pusat bangkitan pergerakan berlokasi disepanjang jalan, seperti perdagang, pendidikan dan industri.

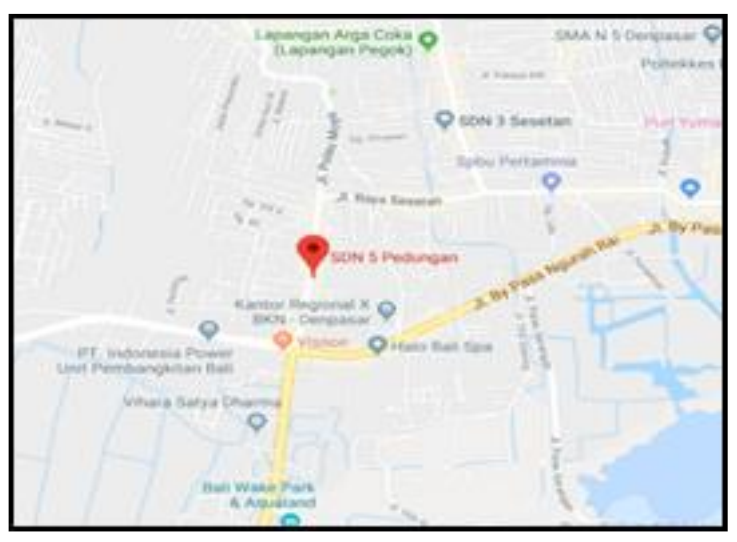

Gambar 1. Lokasi SDN 5 Pedungan (Sumber: Google Maps, 2020)

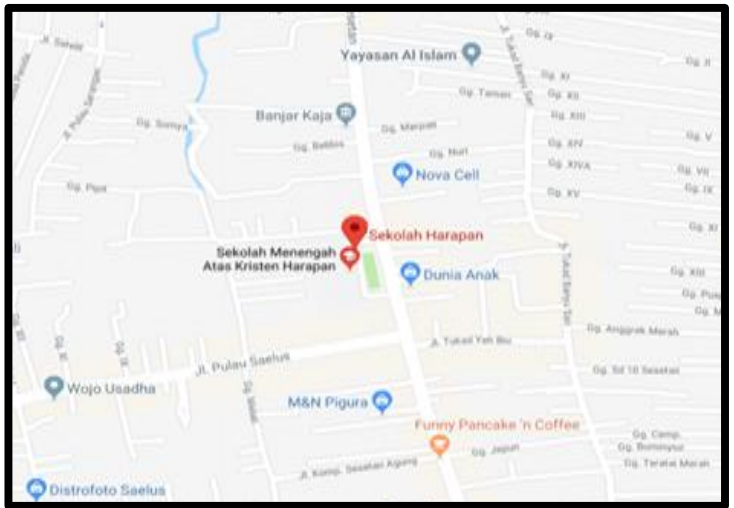

Gambar 2. Lokasi Sekolah Harapan

(Sumber: Google Maps, 2020)

\subsection{Waktu Survey}

Survey dilakukan hari selasa 10 Desember 2019 diambil hari tersebut karena pada hari tersebut merupakan hari efektif. Hari efektif adalah dari hari senin sampai hari jumat. Survey dilaksanakan dalam jangka waktu berkala yaitu pada jam sibuk pagi 06.30-08.30 wita dan jam sibuk siang 12.00-14.00 wita dengan menggunakan kamera.

\subsection{Metode Pengambilan Data}

Data pada penelitian ini dapat dibedakan menjadi 2 bagian yaitu:

\subsubsection{Data primer}

Data primer adalah data yang didapatkan dengan melakukan penelitian langsung dilapangan. Data primer pada penelitian ini adalah data kecepatan tempuh kendaraan yang diambil kemudian dikelompokan berdasarkan jenis kendaraan. Jenis kendaraan dikelompokan dalam sepeda motor, kendaraan ringan dan 
kendaraan berat dengan masing-masing sampel tiap jenis kendaraan adalah maksimum 50 (lima puluh) kendaraan. Proses ini dilakukan dengan perhitungan manual yaitu menghitung waktu dari sebelum ZoSS dan sesudah ZoSS pengamatan dengan menggunakan stopwatch kemudian dibagi dengan jarak tempuhnya yaitu $100 \mathrm{~m}$.

\subsubsection{Data skunder}

Data skunder adalah data yang didapatkan dari PU atau instansi-istansi terkait seperti jumlah penduduk didaerah terkait dan internet seperti google maps untuk memproleh peta lokasi penelitian.

\subsection{Metode Analisis Data}

Berdasarkan data yang diproleh dari hasil survey dilapangan, kemudian data tersebut diolah. Adapun langkahlangkahnya adalah sebagai berikut:

1. Analisis kecepatan kendaraan menggunakan persamaan 2 . Selanjutnya kecepatan rata rata dipakai untuk menentukan persentase kendaraan patuh.

2. Menentukan persentase kendaraan patuh menggunakan persamaan 1. Yang mana persentase kendaraan patuh merupakan tolak ukur efektifitas ZoSS.
4 HASIL DAN PEMBAHASAN

\subsection{Analisis Efektivitas ZoSS SDN 5 Pedungan}

Data perhitungan yang digunakan untuk mencari tingkat efektivitas ZoSS di SDN 5 Pedungan adalah data kecepatan rata-rata kendaraan dari pukul 06.30 14.00 WITA.

\subsubsection{Jumlah kendaraan patuh saat melintasi ZoSS}

Kendaraan dianggap patuh apabila kecepatan kendaraan saat melintasi ZoSS $\leq$ $30 \mathrm{~km} / \mathrm{jam}$. Maka didapat jumlah kendaraan patuh saat melintasi ZoSS seperti pada Tabel 2.

Tabel 2. Jumlah Kendaraan Patuh Saat Melintasi ZoSS di SDN 5 Pedungan

\begin{tabular}{cccc}
\hline Arah & $\begin{array}{c}\text { Jenis } \\
\text { Kendaraan }\end{array}$ & $\begin{array}{c}\text { Jumlah } \\
\text { Sampel }\end{array}$ & $\begin{array}{c}\text { Jumlah } \\
\text { Kendaraan } \\
\text { Patuh }\end{array}$ \\
\hline Utara & MC & 50 & 13 \\
ke & LV & 50 & 23 \\
Selatan & HV & 50 & 29 \\
Selatan & MC & 50 & 21 \\
ke & LV & 50 & 19 \\
Utara & HV & 50 & 23 \\
\hline
\end{tabular}

MC: motor cycle, $L V$ : light vehicle, $H V$ : heavy vehicle

Dari Tabel 2 dapat dijelaskan bahwa jumlah kendaraan patuh saat melintasi ZoSS arah utara ke selatan untuk MC adalah 13 kendaraan, LV adalah 23 kendaraan, sedangkan HV adalah 29 kendaraan. Untuk arah selatan ke utara MC adalah 21 kendaraan, LV adalah 19 kendaraan, dan HV adalah 23 kendaraan. 


\subsubsection{Prosentase tingkat kepatuhan kendaraan saat melintasi ZoSS}

Menentukan prosentase tingkat kepatuhan kendaraan saat melintasi ZoSS dengan menggunakan persamaan 1 dan dari Tabel 2 dimana jumlah kendaraan patuh untuk MC sebanyak 13 kendaraan dari sample 50 kendaraan, maka:

$$
\begin{aligned}
& \frac{\sum P}{N} \times 100 \%=\frac{13}{50} \times 100 \% \\
& =26 \%
\end{aligned}
$$

Untuk perhitungan selanjutnya dapat dilihat pada Tabel 3.

Tabel 3. Prosentase Kepatuhan Kendaraan Saat Melintasi ZoSS di SDN 5 Pedungan

\begin{tabular}{ccc}
\hline Arah & $\begin{array}{c}\text { Jenis } \\
\text { Kendaraan }\end{array}$ & $\begin{array}{c}\text { Prosentase } \\
\text { Kepatuhan (\%) }\end{array}$ \\
\hline Utara ke & MC & 26 \\
Selatan & LV & 46 \\
& HV & 58 \\
Selatan ke & MC & 42 \\
Utara & LV & 38 \\
\multicolumn{2}{c}{ Rata-rata } & 46 \\
\multicolumn{2}{c}{ HV } & $42.67 \%$ \\
\hline
\end{tabular}

Dari Tabel 3 dapat dijelaskan bahwa jumlah prosentase kendaraan patuh saat melintasi ZoSS arah utara ke selatan untuk MC adalah 26\%, LV adalah $46 \%$ dan HV adalah 58\% sedangkan arah selatan ke utara untuk MC adalah 42\%, LV adalah $38 \%$ dan HV adalah $46 \%$. Rata-rata prosentase kendaraan saat melintasi ZoSS di SDN 5 Pedungan adalah $42.47 \%$.

\subsubsection{Tingkat efektivitas ZoSS}

Menentukan tingkat efektivitas ZoSS dengan menggunakan Tabel 1 dan Tabel 3, maka tingkat Efektivitas ZoSS dapat dilihat pada Tabel 4.

Tabel 4. Tingkat Efektivitas ZoSS di SDN 5 Pedungan

\begin{tabular}{ccc}
\hline Arah & $\begin{array}{c}\text { Jenis } \\
\text { Kendaraan }\end{array}$ & $\begin{array}{c}\text { Tingkat } \\
\text { Efektivitas ZoSS }\end{array}$ \\
\hline Utara ke & MC & Kurang Efektif \\
Selatan & LV & Cukup Efektif \\
& HV & Cukup Efektif \\
Selatan ke & MC & Cukup Efektif \\
Utara & LV & Kurang Efektif \\
\multicolumn{2}{c}{ Rata-rata } & Cukup Efektif \\
\hline
\end{tabular}

Dari Tabel 3 dan Tabel 4 dapat dijelaskan bahwa rata-rata prosentase jumlah kendaraan patuh saat melintasi ZoSS di SDN 5 Pedungan adalah $42.67 \%$ yang artinya ZoSS berada pada tingkat yang cukup efektif.

\subsection{Analisis Efektivitas ZoSS Sekolah Harapan \\ Data kecepatan rata-rata kendaraan} dari pukul 06.30 - 14.00 WITA digunakan untuk mencari tingkat efektivitas ZoSS di Sekolah.

\subsubsection{Jumlah kendaraan patuh saat melintasi ZoSS}

Kendaraan dianggap patuh apabila kecepatan kendaraan saat melintasi ZoSS $\leq$ $30 \mathrm{~km} / \mathrm{jam}$. 
Maka didapat jumlah kendaraan patuh saat melintasi ZoSS seperti pada Tabel 5.

\begin{tabular}{|c|c|c|c|}
\hline Arah & $\begin{array}{c}\text { Jenis } \\
\text { Kendaraan }\end{array}$ & $\begin{array}{l}\text { Jumlah } \\
\text { Sampel }\end{array}$ & $\begin{array}{l}\text { Jumlah } \\
\text { Kendaraan } \\
\text { Patuh }\end{array}$ \\
\hline Utara & MC & 50 & 12 \\
\hline ke & LV & 50 & 16 \\
\hline Selatan & $\mathrm{HV}$ & 50 & 23 \\
\hline Selatan & $\mathrm{MC}$ & 50 & 10 \\
\hline $\mathrm{ke}$ & LV & 50 & 11 \\
\hline Utara & $\mathrm{HV}$ & 50 & 25 \\
\hline
\end{tabular}

Dari Tabel 5 dapat dijelaskan bahwa jumlah kendaraan patuh saat melintasi ZoSS arah utara ke selatan untuk MC adalah 12 kendaraan, LV adalah 16 kendaraan, sedangkan $\mathrm{HV}$ adalah 23 kendaraan. Untuk arah selatan ke utara MC adalah 10 kendaraan, LV adalah 11 kendaraan, dan HV adalah 25 kendaraan.

\subsubsection{Prosentase tingkat kepatuhan kendaraan saat melintasi ZoSS}

Menentukan prosentase tingkat kepatuhan kendaraan saat melintasi ZoSS dengan menggunakan persamaan 1 dan dari Tabel 5 dimana jumlah kendaraan patuh untuk MC sebanyak 12 kendaraan dari sample 50 kendaraan, maka:

$$
\begin{aligned}
& \frac{\sum P}{N} \times 100 \%=\frac{12}{50} \times 100 \% \\
& =24 \%
\end{aligned}
$$

Untuk perhitungan selanjutnya dapat dilihat pada Tabel 6 .
Tabel 6. Prosentase Kepatuhan Kendaraan

\begin{tabular}{|c|c|c|}
\hline Arah & $\begin{array}{c}\text { Jenis } \\
\text { Kendaraan }\end{array}$ & $\begin{array}{c}\text { Prosentase } \\
\text { Kepatuhan }(\%)\end{array}$ \\
\hline \multirow{3}{*}{$\begin{array}{l}\text { Utara ke } \\
\text { Selatan }\end{array}$} & $\mathrm{MC}$ & 24 \\
\hline & LV & 32 \\
\hline & HV & 46 \\
\hline \multirow{3}{*}{$\begin{array}{c}\text { Selatan ke } \\
\text { Utara }\end{array}$} & $\mathrm{MC}$ & 20 \\
\hline & LV & 22 \\
\hline & HV & 50 \\
\hline \multicolumn{2}{|c|}{ Rata-rata } & $32.34 \%$ \\
\hline
\end{tabular}
Saat Melintasi ZoSS di Sekolah Harapan

Dari Tabel 6 dapat dijelaskan bahwa jumlah prosentase kendaraan patuh saat melintasi ZoSS arah utara ke selatan untuk MC adalah 24\%, LV adalah 32\% dan HV adalah $46 \%$ sedangkan arah selatan ke utara untuk MC adalah 20\%, LV adalah $22 \%$ dan HV adalah $50 \%$. Rata-rata prosentase kendaraan saat melintasi ZoSS di Sekolah Harapan adalah 32.34\%.

\subsubsection{Tingkat efektivitas ZoSS}

Menentukan tingkat efektivitas ZoSS dengan menggunakan Tabel 1 dan Tabel 6, maka tingkat Efektivitas ZoSS dapat dilihat pada Tabel 7.

Tabel 7. Tingkat Efektivitas ZoSS di SDN 5 Pedungan

\begin{tabular}{ccc}
\hline Arah & $\begin{array}{c}\text { Jenis } \\
\text { Kendaraan }\end{array}$ & $\begin{array}{c}\text { Tingkat } \\
\text { Efektivitas ZoSS }\end{array}$ \\
\hline Utara ke & MC & Kurang Efektif \\
Selatan & LV & Kurang Efektif \\
& HV & Cukup Efektif \\
Selatan ke & MC & Kurang Efektif \\
Utara & LV & Kurang Efektif \\
\multicolumn{2}{c}{ Rata-rata } & Kurang Efektif \\
\hline
\end{tabular}


Dari Tabel 6 dan Tabel 7 dapat dijelaskan bahwa rata-rata prosentase jumlah kendaraan patuh saat melintasi ZoSS di Sekolah Harapan adalah 32.34\% yang artinya ZoSS berada pada tingkat yang cukup efektif.

\section{SIMPULAN DAN SARAN}

\subsection{Simpulan}

Berdasarkan analisis dan diproleh hasilnya, maka dapat kesimpulan bahwa penerapan ZoSS di Kecamatan Denpasar Selatan belum optimal atau tidak efektif. Karena dari sampel ZoSS yang digunakan pada penelitian ini yaitu SDN 5 Pedungan dan Sekolah Harapan, rata-rata prosentase kendaraan patuh saat melintasi ZoSS untuk SDN 5 Pedungan $42.67 \%$ yang artinya ZoSS cukup efektif dan Sekolah Harapan $32.34 \%$ yang artinya ZoSS kurang efektif.

\subsection{Saran}

Dari hasil yang didapat, maka beberapa saran dari penelitian ini sebagai berikut:

1. Diperlukan peran kepolisian setempat untuk memberikan sangsi terhadap para pengendara yang melanggar rambu batas kecepatan yang telah ditetapkan.

2. Pemerintah Kecamatan Denpasar Selatan wajib mensosialisasikan ZoSS agar masyarakat umum tau apa tujuan dan fungsi diterapkanya ZoSS.

3. Pita pengaduh/pita kejut dikawasan ZoSS perlu dipertebal sehingga pengendara secara otomatis memperlambat kecepatan saat akan melintasi kawasan ZoSS.

4. Perlu melengkapi rambu dan fasilitas ZoSS agar memenuhi standar aturan yang telah ditetapkan.

\section{DAFTAR PUSTAKA}

Anonim. (1997). Manual Kapasitas Jalan Indonesia (MKJI). Jakarta.

Anonim. (2006). Peraturan Direktur Jendral Perhubungan Darat No: SK 3263/AJ.403/DRJD Tahun 2006 tentang Uji Coba Zona Selamat Sekolah di 11 Kota di Pulau Jawa. Jakarta.

Anonim. (2014). Peraturan Direktur Jendral Perhubungan Darat No: SK 1304/AJ.403/DRJD Tahun 2014 tentang Zona Selamat Sekolah (ZoSS). Jakarta.

Anonim. (2018). Peraturan Direktur Jendral Perhubungan Darat No. SK. 3582/AJ. 403/DRDJ/2018 tentang Pedoman Teknis Pemberian Prioritas Keselamatan dan Kenyamanan Pejalan Kaki Pada Kawasan Sekolah Melalui Penyediaan Zona Selamat Sekolah. Jakarta.

BPS. (2018). Denpasar Dalam Angka. Denpasar. 
Ferryanto, I. W. (2013). Evaluasi Terhadap Efektivitas Operasional Zona Selamat Sekolah (ZoSS). Universitas Udayana.

Nurhakim, Sriastuti, D. A. N., \& Ardantha, I. M. (2018). Efektivitas Zona Selamat Sekolah dan Kinerja Ruas Jalan (Studi Kasus: ZoSS SD Negeri 4 Dalung). PADURAKSA, 7(1).

Sugiono. (2012). Metode Penelitian Kuantitatif, Kualitatif dan $R \& D$. Bandung: Alfabeta. 